\author{
Military Technical \\ College \\ Kobry El-Kobba \\ Cairo, Egypt
}

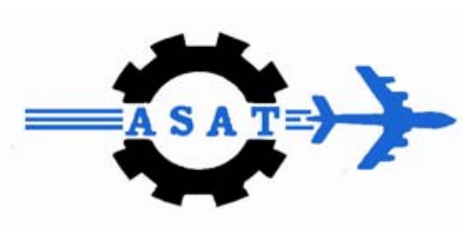

12-th International

Conference on

Aerospace Sciences \&

Aviation Technology

\title{
NEWRAL NETWORK CONTROL FOR RE-ENTRY VEHICLE DURING TAEM PHASE
}

Jong-hun Kim, Jo-ha Baek*, Dae-woo Lee**, Kyeum-rae Cho***, Min-shik Roh*

\begin{abstract}
This paper describes a result of the guidance and control for re-entry vehicle during TAEM phase. TAEM phase (Terminal Aerial Energy Management phase) has many conditions, such as density, velocity, and so on. Under these conditions, we have optimized trajectory and other states for guidance in TAEM phase. Optimized states consist of 7 variables, down range, cross range, altitude, velocity, flight path angle, vehicle's azimuth and flight range. For optimizing, we dealt with DIDO as a programming tool, and we used feedback linearization with neural network for control re-entry vehicle. By back propagation algorithm, vehicle dynamics is approximated to real. New command can be decided using the approximated dynamics, delayed command input and plant output, control system. Using this control law, we tracked 7 states, made by optimization.
\end{abstract}

\section{KEY WORDS}

Re-entry vehicle, TAEM Phase, Neural network control, Trajectory Optimization, NARMA-L2

*Graduate Student, Dpt. of Aerospace, Pusan National Univ., Busan, KOREA ${ }^{* *}$ Associate professor, Dpt. of Aerospace, Pusan National Univ., Busan, KOREA ${ }^{* * *}$ Professor, Dpt. of Aerospace, Pusan National Univ., Busan, KOREA 


\section{INTRODUCTION}

In recent years, concern of re-entry space vehicle as space transportation system has increased for service the International Space Station (ISS). Countries have researched for this to follow this trend. Some studies of the re-entry problem, return to earth, will become more important.

Re-entry system consists of three phases, entry phase, TAEM (Terminal Aerial Energy Management) phase, A/L (Approach and Landing) phase. TAEM phase, second phase of re-entry system, is operated at large distribution of altimeter, from $3 \mathrm{~km}$ to $27.5 \mathrm{~km}$. In this area, density, temperature and speed of sound are depend on altitude strictly. By this reason, three areas of speed, subsonic, transonic and supersonic, exist in TAEM phase.

The objective of TAEM phase is to satisfy the requirements that space vehicle enter to $A / L$ phase safety. For this reason, energy dissipation exists at TAEM phase, using velocity adjustment and making trajectory. In addition, the re-entry vehicle should straightly flight along the landing site. By the objective of TAEM phase and the environment condition, the vehicle in TAEM phase is led onto the peculiar trajectory profile to turn around HAC (Heading Alignment Cylinder). This can be accomplished by control of vehicle's bank angle and angle of attack. Generally, bank angle influences horizontal trajectory that is constituted by down-range and cross-range, and angle of attack influences vertical trajectory that is related with altitude. The control of bank angle gives strong effect in aspect of energy dissipation, but it has a shortcoming of slow response time. On the other hand, the control of angle of attack has a fast response speed due to a short period actuation, but may have stability problem because it is sensitive to pitch maneuver.

In this paper, optimization method is explained briefly with optimal reference trajectory in TAEM phase. Control law, feedback linearization with neural network, is applied to track reference trajectory and other states. To control bank angle, we use heading angle as tracking reference profile. 


\section{OPTIMAL TRAJECTORY}

HOPE-X that has been developed in the National Aerospace Laboratory and the National Aerospace Development Agency in Japan is applied in this paper. HOPE$X$ 's mass is $8150 \mathrm{~kg}$ and reference area is $65 \mathrm{~m}^{2}$. Aero coefficient of HOPE-X is quoted in [1]. It is shown in Fig.1 and Fig.2. Because of lack of data below Mach number 0.4 , values in that area are presumed as constant values. However, velocity in real final condition is in about Mach number 0.3. It is prospected to have low reliability.

\section{Equation of motion}

To make optimal trajectory problem, we can assume that airframe is particle. If reentry vehicle is a target object, we can't neglect the effect of centrifugal force and we need to assume the earth as globe. However, in this TAEM phase, vehicle's altitude, altitude from the surface of the earth and length of flight locus is much smaller than earth radius.

Finally, we can assume that the surface of the earth is 2-Dimensional surface and flight of re-entry vehicle doesn't have thrust force because it is gliding. With the vehicle's velocity element, direction of drag is opposite and is flight path angle and angle of attack. In Fig.3, you can know expresses on relation of velocity (V), lift (L), drag (D), gravity (W) vectors, flight path angle $(\gamma)$ and angle of attack $(\alpha)$.

As considering coordinate system and gliding condition, we can conduct dynamic equation below.

$$
\begin{gathered}
\dot{V}=-\frac{D}{m}-g \sin \gamma \\
\dot{\gamma}=\frac{L \cos \phi}{m V}-\frac{g}{V} \cos \gamma
\end{gathered}
$$




$$
\begin{aligned}
& \dot{\psi}=\frac{L \sin \phi}{m V \cos \gamma} \\
& \dot{h}=V \sin \gamma \\
& \dot{x}=V \cos \gamma \cos \psi \\
& \dot{y}=V \cos \gamma \sin \psi
\end{aligned}
$$

Lift coefficient is expressed by Mach number and angle of attack. Mach number is affected by density and temperature. Drag (D) and lift (L) required by dynamic equations are function of lift coefficient, velocity, vehicle reference area (S) and density $(\rho)$. It is described in equation (7). To decide density $(\rho)$, we use atmosphere model, US76.

$$
D=\frac{\rho S C_{D} V^{2}}{2}, L=\frac{\rho S C_{L} V^{2}}{2}
$$

\section{Solving optimal trajectory}

Before making optimal trajectory, we must decide boundary condition, cost function, constraints and dynamic equation. Design of boundary condition is to suppose that the vehicle is un-powered flight. To connect entry phase, TAEM phase and A/L phase, we can decide initial and final conditions. These are below in Table 1.

Flight in optimal trajectory, demanded in this paper, must have stability and approach a straight trajectory between vehicle and landing site. Also, this must consume energy for the safe arrival into $A / L$ phase. For these reasons, stability of re-entry vehicle is controlled by adjustment of dynamic pressure and energy consumption can be achieved by adjustment of flight distance. These adjustment methods can be made from controlled bank angle and angle of attack. 
Consequently, bank angle and angle of attack become the control input, and angle of attack is limited through dynamic pressure as performance index. Because of large variation of density according to altitude in TAEM phase, it is difficult to keep up constant dynamic pressure. However, difference between target dynamic pressure and actual dynamic pressure will be minimum, made from limited angle of attack. That is, minimum value of variation of dynamic pressure leads to make a trajectory, circle HAC, by combination with constraints. Equation (8) is a performance index for dynamic pressure.

$$
\operatorname{MinJ}=\operatorname{Min} \int_{t_{0}}^{t_{t}}\left(\frac{q-q_{\text {target }}}{q_{\text {target }}}\right)^{2} d t
$$

In guidance, control input for lateral motion is bank angle, and control input for vertical motion is angle of attack. Range of control inputs is limited by physically reasonable values. The ranges of angle of attack and bank angle are below.

$$
-90^{\circ} \leq \sigma \leq 90^{\circ}, \quad 0^{\circ} \leq \alpha \leq 10^{\circ}
$$

Also, flight distance is considered. Since it is influence energy consumption, force effect of bank angle to increase. Limited range of flight distance is below.

$$
0 \leq s \leq s_{f}, \quad s\left(t_{f}\right)=s_{f}
$$

Using these equation and constraints, we can make optimal trajectory. Results of these are shown from Fig.4 to Fig. 17 .

\section{CONTROL BY FEEDBACK LINEARIZATION WITH NEURAL NETWORK}

Neural network has used for identification and control systems [2] [3]. Among some kinds of neural network for control, we use feedback linearization, called NARMA-L2 
control. To cancel nonlinearity, neural network approximate linear form from nonlinear model. Re-entry vehicle's equation of motion has nonlinearity. For using classical control PID, it is difficult to make linear form from nonlinear equations. But neural network can make it easy as training using output of dynamics with respect to random input. This network's architecture is back propagation system.

After approximating dynamic system by neural network, using the proposed equations [4] directly can cause realization problems, because we must determine the control input, $u(k)$, based on the output at the same time, $y(k)$. [5]

$$
\begin{aligned}
\hat{y}(k+d)= & f[y(k), y(k-1), \cdots, y(k-n+1), \\
& u(k), u(k-1), \cdots, u(k-m+1)] \\
& +g[y(k), y(k-1), \cdots, y(k-n+1), \\
& u(k), y(k-1), \cdots, u(k-m+1)] \cdot u(k+1)
\end{aligned}
$$

where $d \geq 2$. Using the NARMA-L2 model, we can define the controller

$$
\begin{gathered}
u(k+1)=\frac{y_{r}(k+d)-f[Y, U]}{g[Y, U]} \\
Y=[y(k), \cdots, y(k-n+1)], \quad U=[u(k), u(k-1), \cdots, u(k-n+1)]
\end{gathered}
$$

which is realizable for $d \geq 2$. This controller can be run by previously identified neural network model, NARMA-L2. In this chapter, to make the control input, bank angle, optimal heading angle $(\psi)$ is used for reference input. This system is made by MATLAB Simulink. At Fig.18, we make block diagram, used S-function for setting up nonlinear dynamic equation.

The result to track reference profile is shown fromFig.19 to Fig.26. The graph, Fig.26, presents 2 control inputs; one was made by optimal trajectory and the other by NARMA-L2 controller. In this graph, you can see oscillation area the end of this. This is an original problem of this control system. However, through repeated training, 
we make a good performance. For eliminating this area, at first, dummy at under Mach number 0.3 must be improved. Next, this can be reduced by filtering (as in sliding mode control) [6]. Other graphs are showing error between reference profiles and output by NARMA-L2 controller. As you can see, the results of tracking system are satisfied. Especially, maximum error on cross range is less than 100 meter, and error on azimuth is less than 3 degree.

\section{CONCLUSIONS}

In this paper, we showed what generates optimal trajectory and controls re-entry vehicle, HOPE-X, using feedback linearization with neural network, NARMA-L2. From nonlinear dynamic, as particle of re-entry vehicle, we solved optimal trajectory that can dissipate energy to arrive $A / L$ phase. In control of the optimal trajectory, control input values are angle of attack and bank angle. Control by bank angle is useful to decrease a load of control system and stability, but to approach a straight trajectory between vehicle and the landing site, control by angle of attack that directly adjusts vertical motion must be considered. By constraints of control method and character of TAEM phase, we define performance index that is dynamic pressure.

To track optimal trajectory and profile of states, we use NARMA-L2 control. We make sample to train neural network. This consists of random input and output of equation of motion with respect to this. NARMA-L2 approximates nonlinear model, re-entry vehicle. Although control input oscillate at the end, control system track optimal trajectory with having small error. To reduce oscillation of control input, we must know exact aero coefficient under Mach number 0.3, and use filter.

\section{ACKNOWLEDGMENT}

This paper is a research supported in 2005 by government (Ministry of Education \& Human Resources Development) and Korea Research Foundation. (KRF-2005-003D00059) 


\section{REFERENCES}

[1] Chul Park, Kyoung-Ho Kim, "Conceptual Design of a Rocket-Powered Plane and Its Use For Space Tourism", KSAS International Journal, Vol. 6, No. 2, pp 46-55, (2005)

[2] Hagan, M. T., Demuth, H.B., "Neural Networks for Control", Proceedings of the 1999 American Control Conference, pp 1642-1656, (1999)

[3] Hunt, K. J., Sbarbaro, D., Zbikowski, R., Gawthrop, P.J., "Neural Networks for Control System - A Survey", Automatica, Vol. 28, pp 1083-1112, (1992)

[4] Narendra, K. S., Mukhopadhyay, S., "Adaptive Control Using Neural Networks and Approximate Models", IEEE Transactions on Neural Networks, Vol. 8, pp 475-485, (1997)

[5] De Jesus, O., Pukrittayakamee, A., Hagan, M.T., "A Comparison of Neural Network Control Algorithms", Neural Networks, 2001. Proceedings. IJCNN '01. International Joint Conference on, Vol. 1, pp 521 - 526 (2001)

[6] M. Hagan, H. Demuth, O. De Jesus, "An Introduction to the Use of Neural Networks in Control Systems", International Journal of Robust and Nonlinear Control, Vol. 12, No. 11, pp 959-985, (2002) 


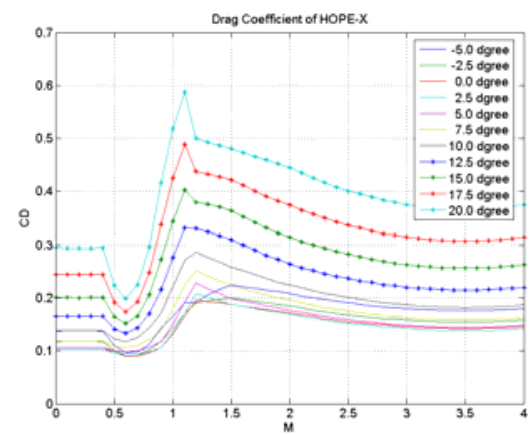

Fig. 1. Drag of coefficients of HOPE-X

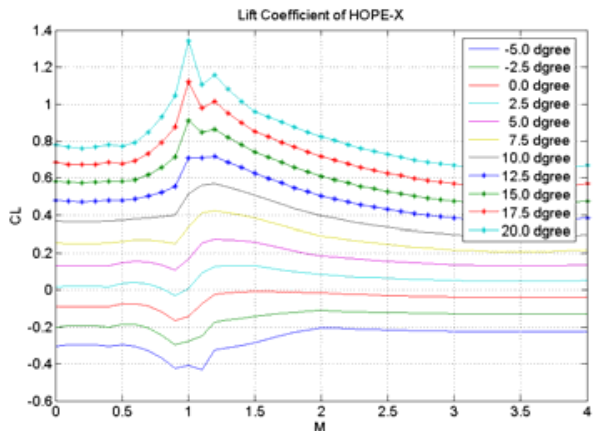

Fig. 2. Lift of Coefficients of HOPE-X

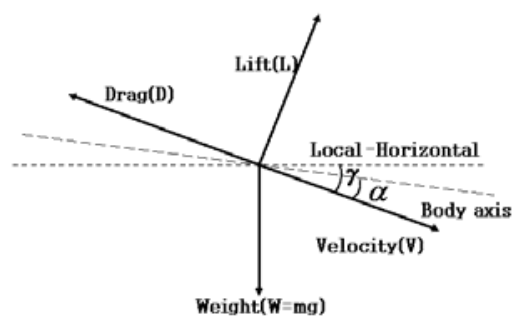

Fig. 3. Free body diagram of re-entry vehicle

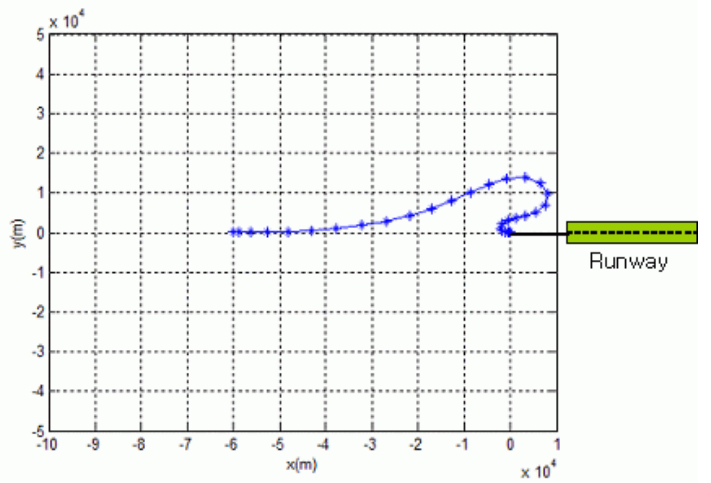

Fig. 4. Trajectory of plane

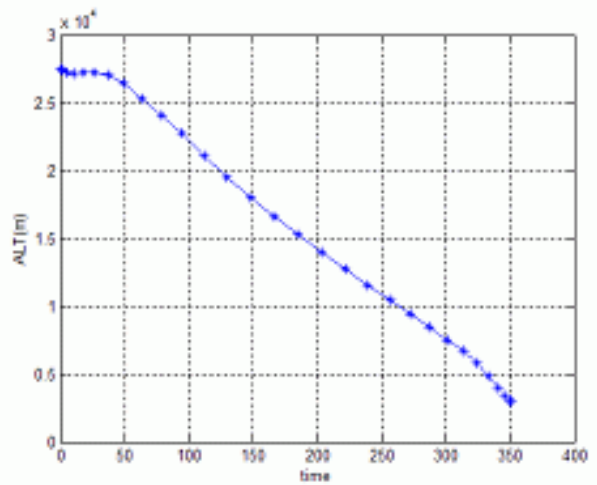

Fig. 5. Time history of altitude 


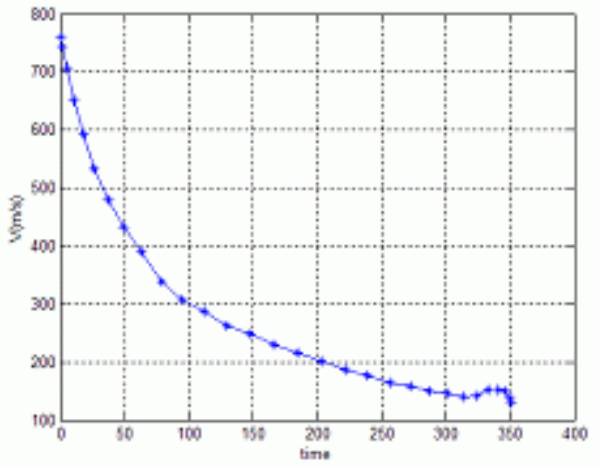

Fig. 6. Time history of velocity

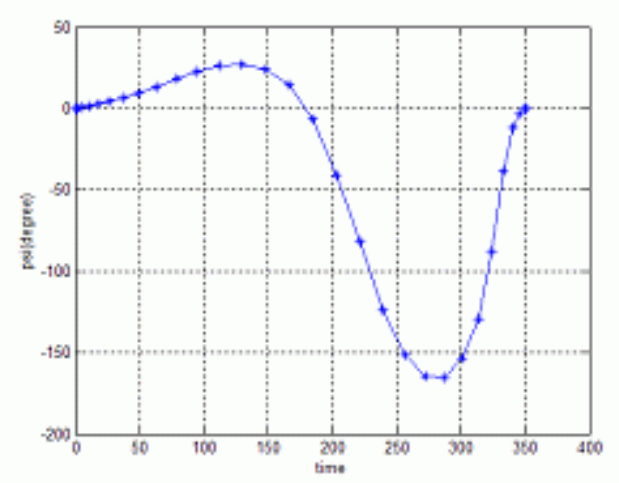

Fig. 8. Time history of heading angle

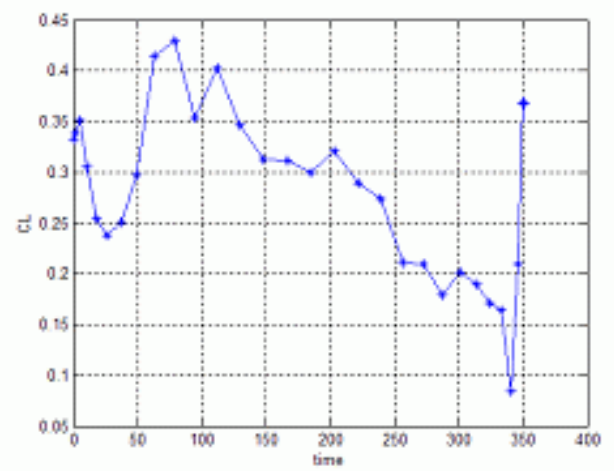

Fig. 10. Time history of lift coefficients

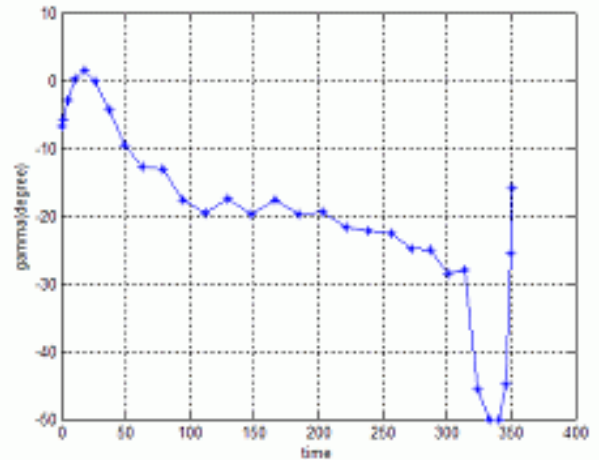

Fig. 7. Time history of flight path angle

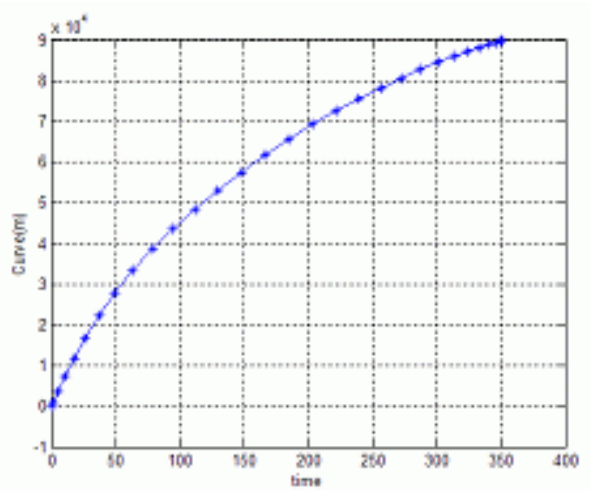

Fig. 9. Time history of flight distance

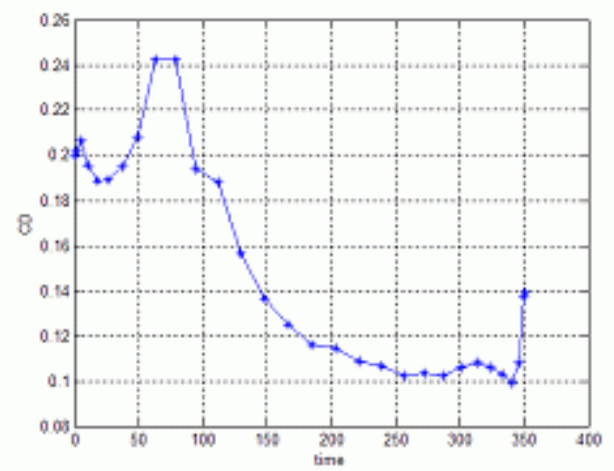

Fig. 11. Time history of drag coefficients 


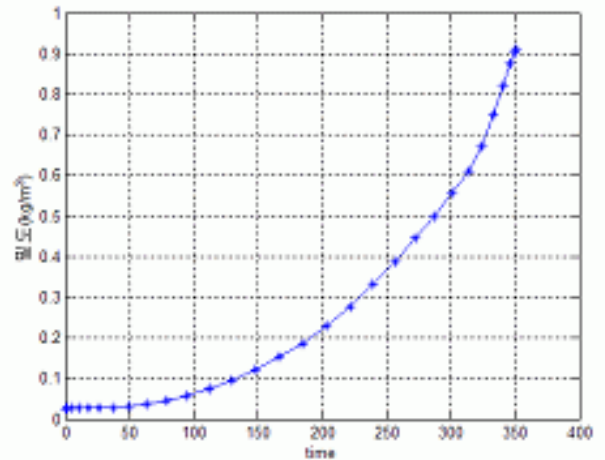

Fig. 12. Time history of atmosphere density

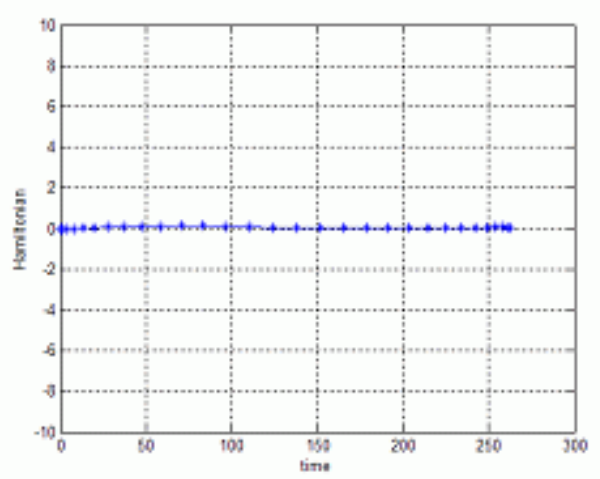

Fig. 14. Time history of hemiltonian value

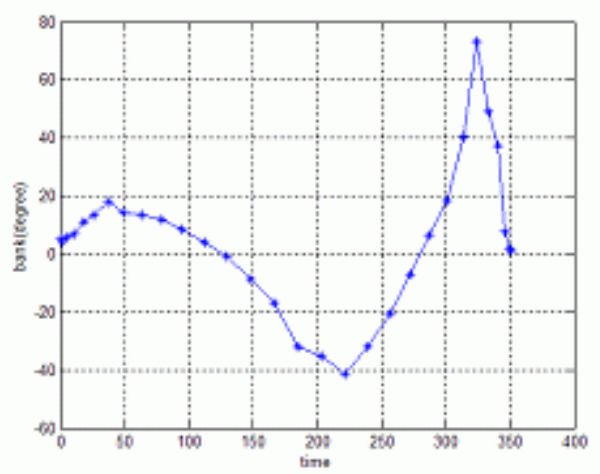

Fig. 16. Time history of bank angle

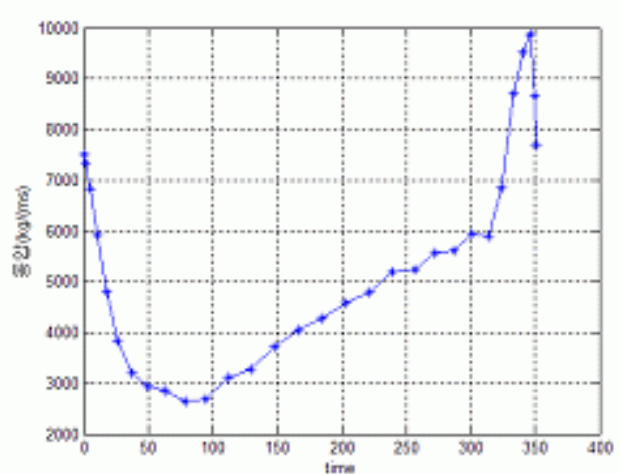

Fig. 13. Time history of dynamic pressure

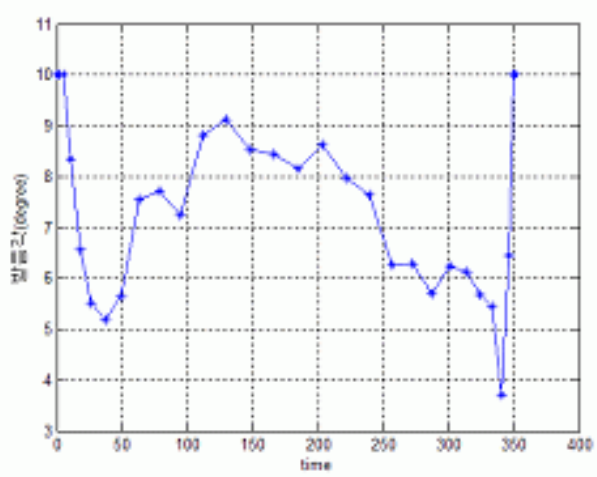

Fig. 15. Time history of angle of attack

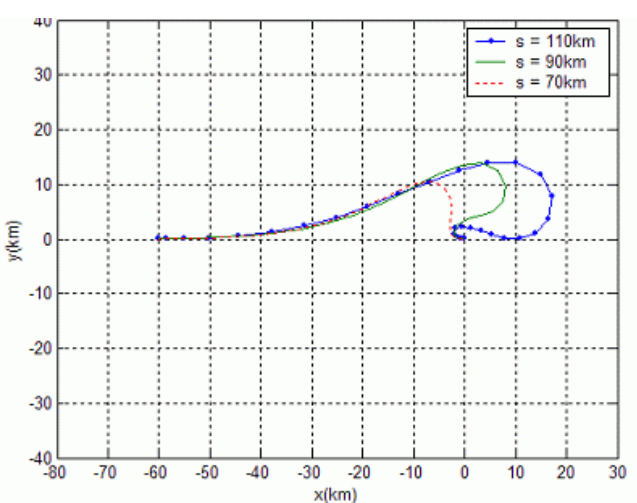

Fig. 17. Trajectory of flight distances 


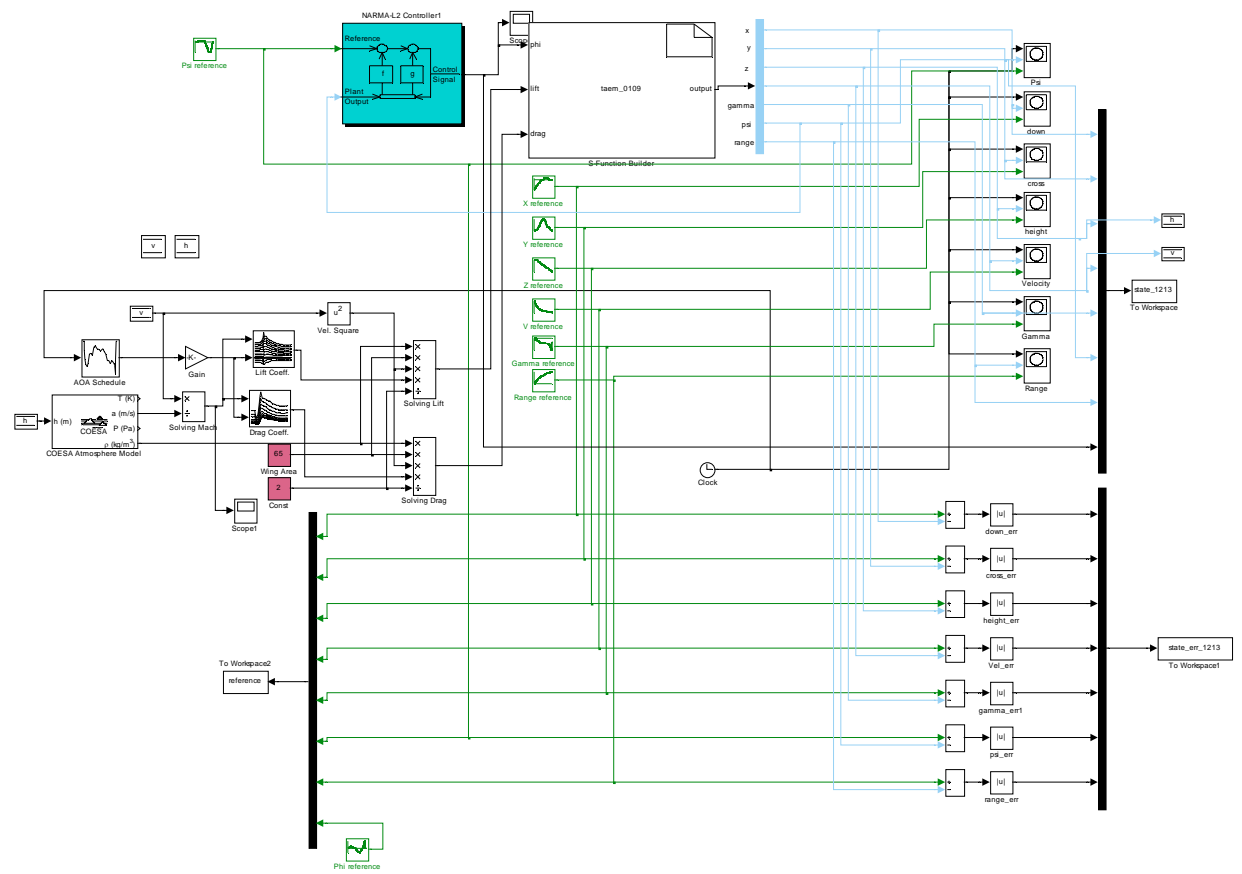

Fig. 18. Block diagram of plant and control system

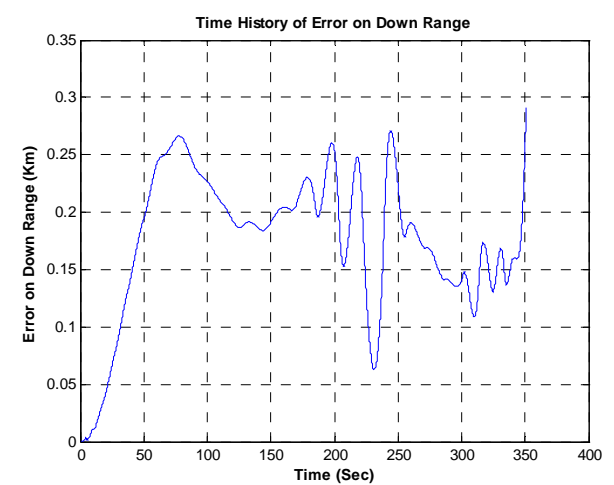

Fig. 19. Time history of down range's error

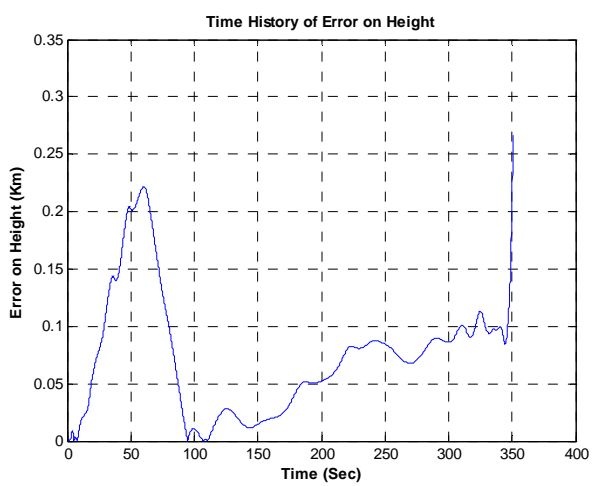

Fig. 21. Time history of altitude's error

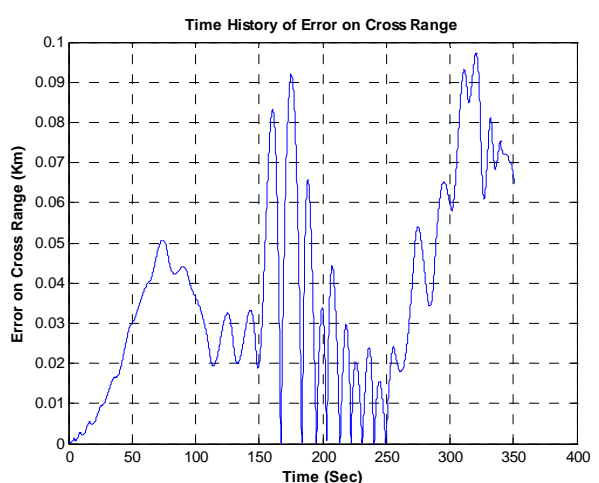

Fig. 20. Time history of cross range's error

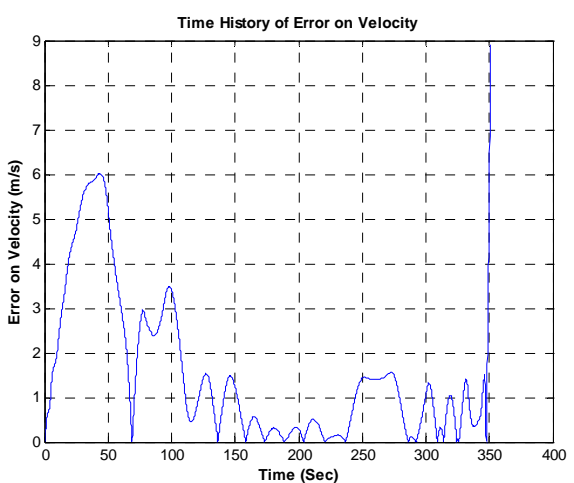

Fig. 22. Time history of velocity's error 


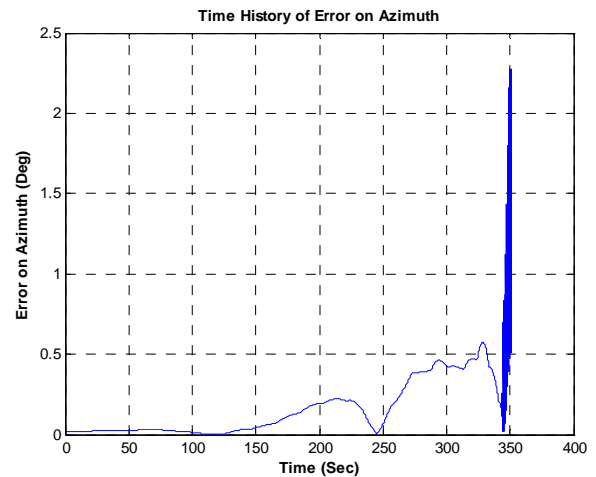

Fig. 23. Time history of azimuth's error

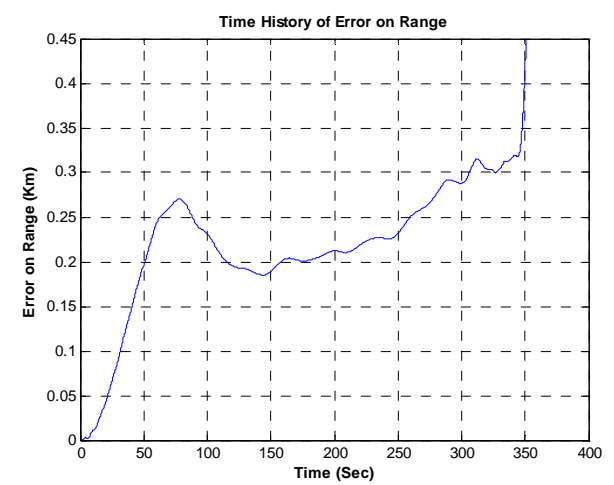

Fig. 25. Time history of flight range's error

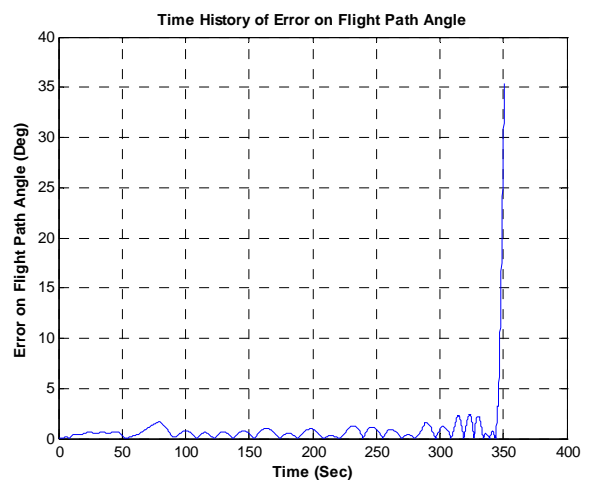

Fig. 24. Time history of flight path angle's error

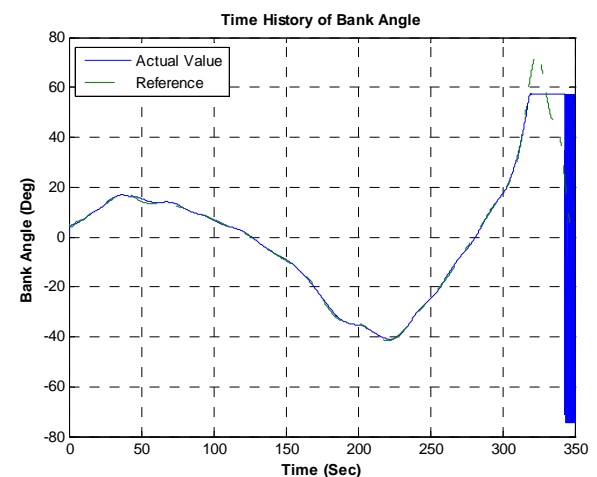

Fig. 26. Time history of control inpuut

Table 1. Initial and final Condition

\begin{tabular}{|c|c|c|}
\hline & $\begin{array}{c}\text { Initial Condition } \\
\text { (Re-Entry | TAEM Interface) }\end{array}$ & $\begin{array}{c}\text { Final Condition } \\
\text { (Re-Entry | TAEM Interface) }\end{array}$ \\
\hline Down-Range & $-60(\mathrm{~km})$ & $0(\mathrm{~km})$ \\
\hline Cross-Range & $0(\mathrm{~km})$ & $0(\mathrm{~km})$ \\
\hline Altitude & $27.5(\mathrm{~km})$ & $3(\mathrm{~km})$ \\
\hline Velocity & $760(\mathrm{~m} / \mathrm{s})$ & $162(\mathrm{~m} / \mathrm{s})$ \\
\hline Flight path angle & $-6.74($ Degree$)$ & $-15.9($ Degree $)$ \\
\hline Azimuth angle & $0($ Degree $)$ & $0($ Degree $)$ \\
\hline Flight Distance & $0(\mathrm{~km})$ & $90(\mathrm{~km})$ \\
\hline
\end{tabular}

